\title{
(q) as a sociolinguistic variable in the Arabic of Gaza City
}

\author{
William Cotter \\ The University of Arizona
}

\begin{abstract}
This study examines the effect of dialect contact between the indigenous residents of Gaza City and refugees originally from the city of Jaffa. The study offers a quantitative sociolinguistic investigation of the variable (q) in the speech of 22 residents of Gaza City. The sample is divided along the lines of dialect background and gender, and it is separated into three age groups. Analysis of the data has revealed that for $(\mathrm{q})$ a significant correlation exists with dialect background and gender, with female speakers and speakers of a Jaffa dialect background showing the highest tendencies to favor the glottal [?] realization for (q). Male speakers in the sample, regardless of their dialect background, showed a tendency to favor the localized $[\mathrm{g}]$ realization of $(\mathrm{q})$.
\end{abstract}

Keywords: sociolinguistics, Gaza Arabic, variation, Palestinian

\section{Introduction}

Representing a complex social, political, and linguistic environment Gaza City, as the largest urban area and de-facto capital of the Gaza Strip, is naturally positioned as a focal point for research being conducted on the besieged territory. The Gaza Strip today is home to over 1.5 million Palestinians with roughly $75 \%$ of the population being of a refugee background (UNRWA, 2013). Of those refugees who have settled in the Gaza Strip, most originally hail from areas in historical Palestine, including, but not limited to, Ramle, Lydd, Jaffa, Bīr is-Sabi', and dozens of Palestinian villages surrounding what is now Gaza which were depopulated or completely destroyed in during the ethnic cleansings which took place in 1948 (Morris, 2008; Pappe, 2006; UNRWA, 2013). This study analyzes the results of dialect contact between one of these refugee communities, Jaffa, and indigenous Gazan Palestinians for the voiceless uvular stop (q). 


\section{The sample and the variable}

Drawing from a larger corpus of 39 speakers, a sample of 10 females and 12 males were selected for the present study. The larger corpus totals roughly twelve hours of audio recordings collected through sociolinguistic interviews conducted during fieldwork in May 2013. The majority of interviews were conducted in speaker's homes, with the help of local university students who acted as research assistants during fieldwork. In addition, the speakers in this study are all currently residents of Gaza City.

Within this sample group of 22 speakers, 7 are refugees originally from the city of Jaffa, $70 \mathrm{~km}$ north of Gaza City and now itself a section of the modern Israeli city of Tel Aviv-Jaffa. ${ }^{1}$ Within this subset of refugee speakers, all but two were born and raised in the Gaza Strip. The two oldest refugee speakers were born in their native Jaffa and expelled during the ethnic cleansing of 1948 (Morris, 2008, pp. 147-155; Pappe, 2006, pp. 102-03). The remaining 15 speakers are all of indigenous Gaza heritage and were born and raised in Gaza City.

The variable realization of $(\mathrm{q})$ in the speech of these 22 speakers (see Table 1) is correlated with three social factors: age, gender, and dialect background. The purpose is to uncover the linguistic ramifications of large scale dialect contact which has been happening in Gaza since 1948. Before presenting statistical analyses of the data, commentary on the variable and its potential social correlates is warranted due to the unique historical factors which have created the linguistic situation under investigation.

Table 1. Speaker demographics

\begin{tabular}{llllll}
\hline Age|Gender & Gazans & $(\cup)$ & & Jaffans \\
\cline { 2 - 3 } & M & F & & M & F \\
\hline $17-39$ & 3 & 3 & 2 & 1 \\
$40-64$ & 3 & 3 & 2 & 0 \\
$65+$ & 2 & 1 & & 0 & 2 \\
Total & & & 22 & & \\
\hline
\end{tabular}

1. Monterescu (2005) provides a thorough spatial and anthropological analysis of Jaffa as a mixed Jewish-Arab town from the creation of the State of Israel to the present day. 


\section{Uvular stop $(q)$}

The uvular stop (q) has been investigated as a sociolinguistic variable in a number of other studies on Arabic speaking communities (e.g. Abd El-Jawad, 1981; Al-Wer, 2007; Haeri, 1997; Holes, 1987). Examples of the variable realization of this phoneme can be seen in the cases of $\mathrm{Amman}^{2}$ and Cairo in example (1) (Al-Wer, 2007; Woidich, 2009).

(1) Modern Standard Arabic

$\begin{array}{ll}\text { Amman } & \text { Cairo } \\ \text { [manțiga] } & \text { [manțiza] } \\ \text { [gahwa] } & \text { [rahwa] } \\ \text { [ga:l] } & \text { [ra:l] } \\ \text { [gari:b] } & {[\text { rari:b] }}\end{array}$

Within Palestinian Arabic three primary realizations have been noted as common for the uvular stop, shown in (2) (Shahin, 2007, p.527).

(2) a. $[\mathrm{k}]-$ voiceless velar stop

b. [?] - glottal stop

c. [g] - voiced velar stop

Additionally, the uvular [q] was once a realization prominent in some communities, particularly Nablus, ${ }^{3}$ as well as other areas of North Palestine including the Druze communities of present day Israel (Abd El-Jawad, 1987; Blanc, 1953). While the literature provides us with a general impression of the variable realization of this phoneme in Palestinian Arabic as a whole, examining it in the dialect of Arabic spoken in Gaza City based on prior research is much more difficult.

Aside from anecdotal commentary on the dialect, Bersträsser (1915) and Salonen $(1979,1980)$ are perhaps the two most reliable scholarly sources that exist on the subject and provide us with much of our current knowledge of the Gaza dialect. ${ }^{4}$ In Bergsträsser's earliest account, the dialect of Gaza is noted as one which features the glottal stop [1] for /q/ (Bergsträsser, 1915, map. 4). However, the descriptions provided by Bergsträsser are limited due to the expansive scope of the study and the reality that a century has passed since data collection took place. This does not wholly diminish Bergsträsser's account but a strong argument could

2. (q) is also a sociolinguistic variable in Amman, so the examples noted here are not the only possible linguistic realizations.

3. Present day Nablus appears to now feature the glottal stop as its primary realization.

4. Although not focusing on Gaza City, Al-Shareef (2002) provides a sociolinguistic analysis of the neighboring dialect of Jabalia refugee camp, north of Gaza City. 
be made that a great deal has changed in Gaza, both socially and linguistically, over the intervening century.

When examining Salonen's later account of the dialect, the texts reflect the strong presence of the voiced velar stop [g] for /q/, in contrast to Bergsträsser's earlier findings on the dialect (Salonen, 1979, p. 20). When commenting on the dialect based on his observations of these two studies, de Jong notes the plausibility that the glottal [?] realization for /q/ shifted towards the voiced velar [g] as a result of direct dialect contact with a number of the Bedouin tribes in the area, as they all feature the velar realization [g] in their dialects (Bergsträsser, 1915, map. 4; de Jong, 2000, p. 590). De Jong additionally notes a number of other Bedouin features in the dialect, which give credence to his hypothesis that the neighboring Bedouin dialects have had a significant influence on the dialect of Gaza City (de Jong, 2000, p. 581). ${ }^{5}$ For the purposes of this study and in light of the data presented below, de Jong's hypothesis on the shift from the glottal [?] towards the velar $[\mathrm{g}$ ] realization of /q/ has been accepted and [g] is being viewed as the variant representative of the native Gaza dialect as it is today.

In contrast to the limited sources available on the position of /q/ in the dialect of Gaza, it is possible to discern a clearer picture from the literature for this phoneme in the dialect of Jaffa. The traditional Jaffa dialect is very much of the urban stock of Palestinian dialects and shares a number of features with other urban dialects in the greater Palestine region. With regard to the feature under investigation in this study, the Jaffa dialect features [?] as its primary realization for /q/ (Horesh, 2000, 2014; Palva, 2006; Shahin, 2007). Thus, within the present sample we have two groups of speakers, indigenous Gazans and Jaffan refugees, who share a degree of contact and whose traditional dialects feature differing realizations for the uvular stop /q/.

\section{Variability in Gaza City}

Al-Wer and Herin (2011) make an important point regarding the frequency with which (q) is examined as a variable in studies on Arabic sociolinguistics and the potential misidentification of the phoneme as a true variable. The authors cite the dialect of Damascus as an example of this point, which features the [?] variant as its standard dialectal realization. The authors note that the occurrence of [q]

5. De Jong expresses serious concerns regarding the reliability of Salonen's informants as actually being of true Gaza City heritage. The author notes that four of the ten speakers in Salonen's texts are of questionable origin based on their own accounts and two thirds of Salonen's texts (by page count) are of questionable authenticity (de Jong 2000, pp. 590-91, see comment 8). As such, Salonen's work must be approached with caution. 
in the dialect is confined predominantly to learned lexical items from Standard Arabic or instances of formal speech. The lack of actual variation between [?] and [q] in the vernacular creates a situation in which /q/ is not variable in Damascus Arabic, despite being labeled as such in previous studies. Beirut and Jerusalem are provided as further examples of this point, wherein /q/ has been misidentified as a variable in situations where no real variation occurs (Al-Wer and Herin, 2011, pp. 60-61).

By examining the corpus of speech collected for this study (see Table 2), it is possible to answer the base question regarding the actual variability of /q/ in Gaza City.

Table 2. Distribution of the dependent variable (q)

\begin{tabular}{llll}
\hline$[\mathrm{g}]$ & {$[\mathrm{p}]$} & [q] & Total \\
\hline 412 & 163 & 43 & 618 \\
\hline
\end{tabular}

When looking at the cross tabulations in Table 2, a clearer picture of the (q) in Gaza City comes into immediate view. The sound [q] is marginal; representing lexical items from Standard Arabic that retained the voiceless uvular stop. 6 Because of this, all lexical items containing tokens of [q] were excluded as they do not occur with any other realization, i.e. there is no variation present. After their exclusion a sample of 575 tokens of (q) remains, divided between two variants, the glottal [?] and voiced velar $[\mathrm{g}]$ stops.

The present situation in Gaza City in regards to $(\mathrm{q})$ bears similarity to that of Amman, where [g] and [?] co-occur alongside each other for the same lexical items (Abd El-Jawad, 1981; Al-Wer, 2007; Al-Wer and Herin, 2011). Additionally, after the 1948 Arab-Israeli War and the creation of the state of Israel, Amman too experienced a sizable influx of Palestinian refugees who have since become a part of the dialect mixture of the city (Al-Wer and Herin, 2011, p. 64). These two cities also form a suitable comparison as both have, as is often common in major urban centers, experienced an influx of migrants from other parts of the region with different dialect backgrounds. However, Gaza City differs from Amman in that while Amman reflects a process of new dialect formation and koineization (Al-Wer, 2007; Kerswill, 2002), Gaza City has always had its own dialect, as it was already an established urban center with a distinctive traditional dialect and a native population (Bergsträsser, 1915; Meyer, 1907; Palva, 2006).

6. The pronunciation of this phoneme as [q] alternated with [k] (retracted [k]), which is quite common in Palestinian and Lebanese dialects. Abd El-Jawad (1981) also provides a useful discussion on lexical class as it relates to /q/. 


\section{Social variables}

Age

While other sociolinguistic studies categorize age based on generational divisions (Labov, 1966; Trudgill, 1974), when researching the Palestinian community, I argue that another divisional makeup is called for. Eckert notes a general division of community studies into two categories as they relate to age: etic and emic. While the former places speakers into arbitrarily determined age groups, it is the latter approach that is applied in the study of Gaza City; an approach that, "groups speakers according to some shared experience of time" (Eckert, 1997, p. 155).

To reflect the unique political and social history which defines many aspects of life for Palestinians in Gaza, age was divided into three groups. The elderly group, over the age of 65, represents both the indigenous community of Gaza and the first generation of refugees that arrived after 1948. The middle aged group was born after the 1948 war but before the October war of 1973. This group represents the first generation of Gazans of both indigenous and refugee heritage born in the Gaza Strip following the refugee influx after 1948 while also experiencing the first wave of large scale dialect contact in Gaza City. This middle generation also potentially had higher degrees of contact with Palestinians of other dialect backgrounds as it was this generation that formed a large part of the Israeli labor market before the borders were closed during the Second Intifada.

Finally, the youngest age group was born following the 1973 war and grew up experiencing the First and Second Palestinian Intifadas. The youngest age group represents the second generation of refugee speakers as well as the youngest generation of indigenous Gazans and provides a view of the dialect of Gaza City as it is today in the wake of large scale dialect contact. Categorizing informants based on political events, in reality wars, appears on the surface to be an unlikely way of delimiting the speech community. However, given the unique history of Palestinians, these events define life stages and greatly affect the personal experiences, backgrounds, and daily activities of speakers.

\section{Gender}

In the case of gender, earlier sociolinguistic work has shown it to play an important role in linguistic variation and change. Studies conducted in Western, English speaking communities, have shown that women tend to favor the use of standard or 'prestigious' variants more than their male counterparts (Cheshire, 1998; Labov, 1966; Milroy, 1987; Trudgill, 1974). However, in the study of Arabic speaking 
communities an apparent dilemma arises when considering standard or prestigious linguistic forms: the issue of diglossia (Ferguson, 1959). ${ }^{7}$

The phoneme under investigation in the present study presents an illustration of this point. Previous studies have shown that men tend to favor the usage of the Standard Arabic [q], while women often disfavor its usage (Abd El-Jawad, 1981; Haeri, 1997). This creates what appears to be a contradiction with the studies conducted in Western/English speaking communities, where women favor these standard/prestige forms. Through the diglossic nature of Arabic, Standard Arabic and the dialects exist side by side and are utilized for very different purposes and with specific communicative goals in mind. Standard Arabic represents an 'official' standard that is used in formal address, media reports, and literature, but is not the daily language of anyone in the Arabic speaking world. ${ }^{8}$ As such, the notion of the standard in linguistic research on Arabic has been re-oriented towards one based on the local dialect standards for the community being researched.

Speaking on these localized standards in relation to gender and linguistic usage Al-Wer notes that, "The data from various parts of the Arab world show overwhelmingly that Arab men opt for localized and older features while Arab women favor features which have a wider regional acceptance and usage regardless of the status of these features vis-à-vis Classical Arabic" (Al-Wer, 1997, p. 261), i.e. the varieties spoken in the major urban centers of the Middle East. Work on the dialects spoken in Amman and Cairo (Al-Wer, 2007; Haeri, 1997) point to the reality of these local urban standards, which provide researchers with the criteria necessary to make comparisons with the results of sociolinguistic research as it relates to gender in English speaking communities. With these localized concepts of standard in mind, the findings of these studies show us that linguistic communities in the Arabic speaking world closely resemble those of the West in regards to the role of gender in linguistic production.

\section{Dialect background}

Although not unique to the community of speakers being examined in Gaza, the socially identifying marker of one's dialect background is especially important in any study conducted on Gaza or the wider Palestinian community in general.

7. See Milroy (1985) for an extended discussion on the challenges present in tapping into linguistic prestige.

8. The official standard here represents much the same standard as that which was put forth by Bourdieu (1991): i.e. one which is given official status in the linguistic market. 
History has created a scenario in which this community has been afflicted with massive waves of migration and expulsion that has dispersed a once localized group across the wider Middle East. The unique dialect backgrounds of the speakers in this study will be examined as a potentially influential feature in their realizations of the variable under investigation.

Dialect background, which in the case of Gaza City also indexes refugee status, is an emerging social category that has received somewhat limited attention thus far in Arabic sociolinguistics. Al-Wer's work on the formation of the dialect of Amman represents one of the most recent attempts at integrating dialect background into an analysis of language variation and change in an Arabic speaking community to date. ${ }^{9}$ Her analysis of Ammani Arabic has shown dialect background to play an influential role in the realization of linguistic features and the development among the younger generation of Ammani speakers of a new dialect in the Jordanian capital (Al-Wer, 2007).

\section{A note on statistical analysis}

To carry out the quantitative analysis presented in this study, I used the Rbrul statistical package (Johnson, 2009). ${ }^{10}$ Built on the foundation laid down by the earlier VARBRUL/Gold Varb (Sankoff, 1975; Sankoff et al., 2005) platform, Rbrul provides additional statistical capabilities which add greater depth to the types of analyses possible with a given set of data. Crucially, Rbrul was designed by a sociolinguist with the complex and often uneven nature of sociolinguistic data sets in mind. In practical terms this manifests in Rbrul's ability to treat "messy" data sets with a high level of accuracy. This makes it possible to better determine the true levels of significance present in the data despite shortcomings in the distribution of the data across respective cells.

When conducting a step-up step-down analysis of the data, Rbrul reports the $\log$-odds, ${ }^{11}$ as well as the Nagelkerke (1991) $\mathrm{R}^{2}$ and the statistical significance for each of the factors that it includes in the model. For the results presented in this study, in all instances the [?] variant of (q) is treated as the application value in each Rbrul statistical run. As a result, positive log-odds reported for a given factor

9. Holes (1987) provides an additional, earlier account on the importance of dialect background as a social variable in Arabic sociolinguistics.

10. Rbrul is available for free from http://www.danielezrajohnson.com/rbrul.html and runs within $\mathrm{R}$, which is available as a free download from http://www.r-project.org/.

11. Rbrul also reports factor weights, but only log-odds are reported in this study. 
indicate a tendency to favor the [?] variant, whereas negative log-odds reflect a tendency to disfavor the [?] variant (or synonymously, favor the [g] variant). ${ }^{12}$

\section{Findings and discussion}

The examples in (3) reflect the use of this variable in the data set, while Table 3 provides a percentage distribution of the two variants of $(q)$ evidenced in the data:

(3) a. 'before' [ [abil]

b. 'approximately' $\sim$ [ta?ri:ban]

c. 'now' $\sim$ [halre:t]

d. 'heart' $\sim$ [galb]

e. 'he says' $\sim$ [bigu:l]

f. 'up' $\sim$ fo:g]

Table 3. Percentage distribution of (q) between its two dialectal variants

\begin{tabular}{lll}
\hline Variant & Percentage of variants & Tokens \\
\hline$[\mathrm{g}]$ & $72 \%$ & 412 \\
{$[\mathrm{i}]$} & $28 \%$ & 163 \\
Total & & 575 \\
\hline
\end{tabular}

The breakdown of this variable by its respective variants reflects a noticeable tendency for speakers to favor the voiced velar $[\mathrm{g}]$ realization of $(\mathrm{q})$. The underlying complexity of this tendency becomes clearer when examining the interaction between these variants and dialect background, age, and gender.

\section{(q) and dialect background}

While both Gaza and Jaffa are part of the larger community of Palestinian dialects, they differ in their classification as typically being of an urban/sedentary or rural/ Bedouin variety (Cadora, 1992; Palva, 2006).13 We have accepted for the purposes of this study de Jong's assessment that Gaza City is an old urban dialect which has taken on a number of Bedouin characteristics, most importantly for the present

12. For those unfamiliar with quantitative sociolinguistic analysis, Gorman and Johnson (2013) and Johnson (2009) may effectively be jumping straight into the statistical deep end but they represent perhaps the best explanations of the capabilities of Rbrul.

13. Britain (2008) provides a noteworthy discussion on the potential unhelpfulness of creating an urban/rural dichotomy in linguistic studies. 
study a velar $[\mathrm{g}]$ realization of /q/. At the same time Jaffa is accepted to be a dialect of the common urban Palestinian type (de Jong, 2000; Horesh, 2000; Shahin, 2007). Table 4 shows the results of the analysis for the glottal [?] variant and its correlation with dialect background.

Table 4. Rbrul results for $(\mathrm{q})$ by dialect background $\left(\mathrm{R}^{2}=.473 \mathrm{p}=8.23 \mathrm{e}^{-35}\right)$

\begin{tabular}{lllc}
\hline Dialect background & Tokens & \% & Log-odds \\
\hline Jaffa & 198 & $55 \%(\mathrm{~N}=109)$ & 1.539 \\
Gaza & 377 & $14 \%(\mathrm{~N}=54)$ & -1.539 \\
\hline
\end{tabular}

These results point to the role that dialect background plays in the variable realization of (q) in Gaza City. Speakers of Jaffan descent show a clear tendency to favor the use of the glottal [?] variant, which is in line with the standard realization of this variable in the dialect of Jaffa (Horesh, 2000; Palva, 2006). When examining dialect background alongside age and gender as potential correlates of (q) a more complex picture begins to emerge that provides a more in-depth view of the linguistic variation present in Gaza.

\section{(q) and age}

When conducting the Rbrul analysis of (q), age is not reported as a statistically significant factor in the analysis. However, despite an apparent lack of statistical significance, age as a social factor warrants further comment. This examination of age in Gaza City reflects the findings of earlier work and with further research on this community it is possible that a new analysis would find age to play a more statistically significant role.

As a backdrop for the discussion of age in the data collected in Gaza City, Al-Wer's research on Ammani Arabic offers an insightful starting point. Al-Wer found that in her sample from Amman among the older generation of Ammani speakers the tendency was for speakers of Palestinian dialects to favor the use of the [?] variant, what would be considered their input variant, while older Jordanian speakers utilized the [g] variant for this variable. The second generation of speakers in the Amman study showed extreme levels of variation, which the author attributes to the use of a mixture of two dialects. While the third generation of Ammani speakers underwent what Al-Wer refers to as a "social and stylistic reallocation" (Al-Wer, 2007, p. 66) and began to establish new normative characteristics in their speech. Among this generation female speakers favored the [?] variant consistently, while male speakers realized (q) in a more complex situational manner based on the context of the speech environment and the gender and dialect background of their interlocutors (Al-Wer, 2007, p. 66). 
When examining Al-Wer's findings alongside the data from Gaza City, it is possible to note both similarities and marked differences. For comparison purposes Table 5 and Table 6 show the cross tabulations of the dependent variable and age, while separating the two Gaza communities based on their dialect background:

Table 5. Distribution of (q) by age among Gazan speakers

\begin{tabular}{lrrrr}
\hline Age & {$[?]$} & {$[\mathrm{g}]$} & $\%[?]$ & Total \\
\hline $65+$ & 1 & 64 & $2 \%$ & 65 \\
$40-64$ & 7 & 154 & $4 \%$ & 161 \\
$17-39$ & 46 & 105 & $30 \%$ & 151 \\
& & & & 377 \\
\hline
\end{tabular}

Table 6. Distribution of (q) by age among Jaffan speakers

\begin{tabular}{llccc}
\hline Age & {$[\mathrm{r}]$} & {$[\mathrm{g}]$} & $\%[\mathbf{2}]$ & Total \\
\hline $65+$ & 47 & 2 & $96 \%$ & 49 \\
$40-64$ & 25 & 21 & $54 \%$ & 46 \\
$17-39$ & 37 & 66 & $36 \%$ & 103 \\
& & & & 198 \\
\hline
\end{tabular}

For the oldest generation, the data from Gaza City mimic Al-Wer's earlier findings from Amman. The oldest generation of Jaffan speakers in the sample favored the use of their input variant, [?], while the oldest Gazan speakers favored the use of their own input variant, [g]. However, while the middle generation of Al-Wer's study was marked by extreme variability, the variability present in Gaza City is somewhat less profound. Indigenous Gazan speakers of this generation still overwhelmingly favored the use of [ $\mathrm{g}]$ for $(\mathrm{q})$, regardless of their gender, while middle aged Jaffan speakers paint a more variable picture for $(\mathrm{q})$.

Important to note in this middle generation of Jaffan speakers is that no female Jaffans were available for interviews. So the data presented here is based solely on middle aged male Jaffan speakers. Another important point as it relates to this subset of speakers is that the informant which shows the highest use of [?] was also, by his own account, a speaker that uses his native Jaffa dialect at home and with family but speaks differently when interacting with other members of the community. Presumably this speaker was referring, at least in part, to the realization of (q) in his speech. Because of the shortcomings and lack of data in this category of speakers, the inferences that can be drawn on this middle generation are limited.

The youngest generation of speakers provides possibly the most interesting viewpoint, wherein young Gazan speakers, while still favoring the use of [g] show a noticeable intrusion of the [?] variant into their speech (30\% of tokens). At the 
same time, Jaffan speakers of this youngest generation used more tokens of the velar [g] than their native [?] variant, which represents a reversal of the trends from the previous two generations. Interestingly in this youngest generation of Jaffan speakers, virtually all of the tokens of [?] are from female speakers, while the vast majority of tokens of the velar [g] are from male Jaffan speakers. A clear gender differentiation is visible among this youngest generation of Jaffan speakers that could reflect a tendency by Jaffan men to abandon their heritage variant [2] in favor of the localized [g]. The trend witnessed in the youngest generation is supported by the statistical results for (q) and gender.

\section{(q) and gender}

In general, the data in Table 7 reflects a clear differentiation by gender on the use of the glottal variant of (q), with female speakers showing much higher rates of usage for this variant. The results from Gaza City for the distribution of [?] and gender broadly reflect the findings of earlier work on Arabic speaking communities for this variable (Abd El-Jawad, 1981; Haeri, 1997; Schmidt, 1974; Shorrab, 1981). In addition, Al-Wer found a similar situation in Amman, wherein women showed consistent rates of usage of the glottal [?] variant for $(q)$ regardless of their dialect backgrounds (Al-Wer, 2007, p. 66).

Table 7. Rbrul results for $(\mathrm{q})$ by gender $\left(\mathrm{R}^{2}=.473 \mathrm{p}=2.54 \mathrm{e}^{-29)}\right.$

\begin{tabular}{llll}
\hline Gender & Total tokens & \%? & Log-odds \\
\hline $\mathrm{F}$ & 268 & $46 \%(\mathrm{~N}=123)$ & 1.437 \\
$\mathrm{M}$ & 307 & $13 \%(\mathrm{~N}=40)$ & -1.437 \\
\hline
\end{tabular}

The results obtained from Gaza City also reflect the findings of other sociolinguistic work generally as it relates to the tendency for female speakers to favor the use of supra-local variants. ${ }^{14}$ The variant [?] represents a supra-local variant of (q) par excellence. It is noticeable that in the Levant, all city dialects have [?] for (q), or have changed in that direction, e.g. Jerusalem, Damascus, Beirut, Aleppo, Nablus, etc. Operating under the assumption that Gaza City was once a dialect which featured the [?] for this variable but underwent a change to [g], which is reflected

14. I intentionally avoid the term 'prestige' here. Even though [?] is discussed as a prestigious variant elsewhere, it is not a given that the case is the same in Gaza City and in any case the issue of linguistic behaviour, prestige, and gender is complex and merits a detailed discussion which cannot be addressed within the limitations of the current work. Again, see Milroy (1985) for a useful discussion on the challenges of tapping into linguistic prestige. 
in the data by the overwhelming tendency of indigenous Gaza speakers to utilize [g], in present day Gaza [?] would be an incoming form while at the same time serving as a regional standard. In light of these assertions the findings of this study broadly coincide with Labov's principles $I$ \& II in relation to gender and linguistic usage (Labov, 1990, pp. 205-206).

However, while Al-Wer (2007) noted that women in Amman of the second and third generation, regardless of their dialect background, favored the use of the [?] variant, in Gaza City a slightly more complex interaction with gender appears to be taking place. By examining the distribution of (q) by gender with the two communities separated by dialect background, Table 8 and Table 9 make it possible to more clearly see the interaction between gender and linguistic realization.

Table 8. Distribution of (q) by gender among Gazan speakers

\begin{tabular}{lllcl}
\hline Gender & {$[\mathrm{r}]$} & {$[\mathrm{g}]$} & \%? & Total \\
\hline $\mathrm{F}$ & 44 & 142 & $24 \%$ & 186 \\
$\mathrm{M}$ & 10 & 181 & $5 \%$ & 191 \\
& & & & 377 \\
\hline
\end{tabular}

Table 9. Distribution of (q) by gender among Jaffan speakers

\begin{tabular}{llccc}
\hline Gender & {$[\mathrm{l}]$} & {$[\mathrm{g}]$} & $\% ?$ & Total \\
\hline $\mathrm{F}$ & 79 & 3 & $96 \%$ & 82 \\
$\mathrm{M}$ & 30 & 86 & $26 \%$ & 116 \\
& & & & 198 \\
\hline
\end{tabular}

When cross-tabulating gender and dialect background together with the dependent variable it becomes obvious that it is the female speakers of a Jaffa dialect background who most heavily favor the use of the glottal [?] variant. However, although they still heavily favor the use of the velar [g], female Gaza speakers show a noticeable intrusion of the glottal [?] in their speech. Additionally, their rates of glottal realization for $(\mathrm{q})$ are much higher than their male Gazan counterparts. Among the female Gazan speakers in the sample, the speaker who shows the highest rates of [?] usage (26 tokens) has parents who are of a mixed dialect background, with her father being of indigenous Gazan heritage while her mother is originally from the city of Lydd, an area which features [?] for /q/. So this particular speaker was presumably raised in an environment where a mixture of dialects was spoken, but had potentially higher levels of exposure to her mother's dialect ([?] dialect) during her formative years (Palva, 2006; Trudgill, 1983, p. 167) Therefore it is not surprising that she would have acquired a dialect that favors the use of the glottal [?] variant for (q). 
Additionally, it is possible to note an interesting corollary in the data from Gaza City with Al-Wer's earlier findings as it relates to the male speakers in the sample. While Al-Wer found a situation in Amman where there was a clear situational differentiation among male speakers (Al-Wer, 2007, p. 66), a somewhat different, but ultimately related, picture emerges in Gaza City. In the present sample male speakers heavily favored the use of the $[\mathrm{g}]$ variant regardless of their dialect backgrounds and the dialect backgrounds of their interlocutors. Only one male speaker, who was of Jaffan origin, heavily favored the use of the [1] variant and on that occasion he was speaking to a non-native speaker of Arabic and an indigenous Gazan speaker. ${ }^{15}$

\section{Complicating gender in Gaza City}

As noted previously, earlier research on Arabic sociolinguistics has shown the glottal [?] variant of (q) to be a supra-local variant in the Levant and in regards to gender; female speakers often favor these variants in their speech. This is reinforced by the data from Gaza City in the general tendency of female speakers to favor [?]. However, when looking only at the subsample of speakers who are of the youngest generation of indigenous Gaza speakers it may be possible to begin to see the interaction between (q) variants and gender as a result of the massive influx of refugees of [?] dialect backgrounds.

If we postulate that the initial shift from the [?] as noted by Bergsträsser (1915) to the $[\mathrm{g}]$ has gone virtually to completion, a hypothesis at least partially supported by the overwhelming tendency of Gazan speakers of the middle and older generation to favor the velar $[\mathrm{g}]$, then the incoming variant post 1948 would presumably be the [?].16 The distribution of $(\mathrm{q})$ in the speech of the youngest generation of indigenous Gazans is provided in Table 10.

Although the size of this subsample is limited, it reflects the tendency for female Gazan speakers to adopt the incoming variant, [?], at a higher rate than their male counterparts. While at the same time it is plausible that the velar [g] has a form of covert prestige (see Labov, 1994; Trudgill, 1972) in Gaza City, particularly

15. It is important to note, that male speakers from Gaza were not recorded in situations where they were interacting with female speakers who were unrelated to them. It is perfectly possible that a situation similar to that found in Amman holds true in Gaza, namely that the young men of Gaza alternate between the two variants when interacting with women.

16. An extensive study on Bedouin migration patterns in and around what is today the Gaza Strip to my knowledge, does not exist, but is warranted and would be an invaluable resource to linguists working on the dialects of Arabic in the area. 
Table 10. Gender and (q) in the youngest generation of Gazan speakers

\begin{tabular}{lrlcc}
\hline Gender & {$[?]$} & {$[\mathrm{g}]$} & $\% ?$ & Total \\
\hline $\mathrm{F}$ & 40 & 39 & $51 \%$ & 79 \\
$\mathrm{M}$ & 6 & 66 & $8 \%$ & 72 \\
& & & & 151 \\
\hline
\end{tabular}

with male speakers but also potentially with female speakers of Gazan heritage who show high rates of usage for this variant. As previously mentioned, the female speaker from this group who shows the highest rates of [3] usage (26 tokens) is the product of a marriage of mixed dialect backgrounds. It is possible that within the youngest generation of female Gazan speakers the general tendency for women to favor the $[\mathrm{g}]$ variant, as evidenced by the speech of the older generations which overwhelmingly favor $[\mathrm{g}]$, could be giving way as a result of dialect contact and intermarriage between speakers of different dialect backgrounds.

If the situation reflected in the data does represent a change taking place in the dialect of Gaza City as it relates to gender, it would appear to be moving it in the direction of wider regional trends that show higher rates of [?] usage for (q) among female speakers. It is perhaps too early to say with certainty, but with a new generation a future study may show higher rates of [?] usage gaining ground among female indigenous Gazan speakers, with male speakers continuing to opt for the localized Gazan $[\mathrm{g}]$. This is a reality already evidenced in the speech of the youngest generation of Jaffan speakers, which shows female speakers almost categorically realizing $(q)$ as [?], in line with the native realization of $(q)$ in their dialect and wider regional trends, while male Jaffans show a strong tendency towards using the local $[\mathrm{g}]$ realization. However, the present sample is admittedly too limited in scope to draw a firm conclusion. This is merely an area which should be closely considered in future work.

\section{Conclusion}

Through examining the results of Rbrul analysis for (q) in Gaza City it is possible to see a complex linguistic situation emerging in the speech of Gaza City's residents. Both gender background and dialect background show a statistically significant correlation with the variable realization of (q). In this regard it is both women and speakers of Jaffan descent who show the greatest tendency to favor [2], and within these groups female speakers of a Jaffan background show the highest rates of usage of the [?] variant. Male speakers, regardless of their dialect backgrounds, show a strong tendency to favor the localized $[\mathrm{g}]$ realization for $(\mathrm{q})$. 
The data show quite clearly that a change is taking place in Gaza and on the surface it appears to be one which is moving (q) in the direction of wider regional trends for this variable. However, this is but one study on contact between a single refugee community (out of many) and the indigenous residents of Gaza City. Further work that incorporates data from additional refugee communities who today call Gaza home will play an important role in this ongoing research. Additionally, the issues of linguistic prestige, social networks, and the social indexicality of variants of (q) in Gaza City deserve their own in-depth analysis. Future studies that treat these issues will tell sociolinguists a great deal about what (q) means for the speakers who use it and will further add to our knowledge of the linguistic ramifications of dialect contact in the Gaza Strip.

\section{References}

Abd El-Jawad, H. (1981). Lexical and Phonological Variation in Spoken Arabic in Amman. Diss. University of Pennsylvania.

Abd El-Jawad, H. (1987). Cross Dialectal Variation in Arabic: Competing Prestigious Forms. Language in Society, 16(3), 359-367. doi:10.1017/Soo47404500012446

Al-Shareef, J. (2002). Language Change and Variation in Palestine: A Case Study of Jabalia Refugee Camp. Diss. University of Leeds.

Al-Wer, E. (1997). Arabic between reality and ideology. International Journal of Applied Linguistics, 7(2), 251-265. doi:10.1111/j.1473-4192.1997.tboo117.x

Al-Wer, E. (2007). The Formation of the Dialect of Amman: From Chaos to Order. In C. Miller, E. Al-Wer, D. Caubet, \& J. Watson (Eds.), Arabic in the City (pp. 55-76). New York: Routledge.

Al-Wer, E. \& Herin, B. (2011). The Lifecycle of Qaf in Jordan. Langage Et Societe, 138, 59-76. doi:10.3917/Is.138.0059

Bergsträsser, G. (1915). Sprachatlas Von Syrien Und Palastina. Leipzig: Hinrichs.

Blanc, H. (1953). Studies in North Palestinian Arabic; Linguistic Inquiries among the Druzes of Western Galilee and Mt. Carmel. Jerusalem: Israel Oriental Society.

Bourdieu, P. (1991). Language and Symbolic Power. Cambridge, MA: Harvard University Press

Britain, D. (2008). "Big Bright Lights" Versus "Green and Pleasant Land"?: The Unhelpful Dichotomy of 'Urban' Versus 'Rural' in Dialectology. In E. Al-Wer \& R. de Jong (Eds.), Arabic Dialectology (pp. 223-48). Leiden: Brill.

Cadora, F. J. (1992). Bedouin, Village, and Urban Arabic: An Ecolinguistic Study. Leiden: Brill.

Cheshire, J. (1998). Linguistic Variation and Social Function. In J. Coates (Eds.), Language and Gender: A Reader (pp. 29-41). Oxford: Blackwell.

de Jong, R.E. (2000). A Grammar of the Bedouin Dialects of the Northern Sinai Littoral: Bridging the Linguistic Gap between the Eastern and Western Arab World. Leiden: BRILL.

Eckert, P. (1997). Age as a Sociolinguistic Variable. In F. Coulmas (Eds.), The Handbook of Sociolinguistics (pp. 151-67). Oxford: Blackwell.

Ferguson, C. A. (1959). Diglossia. Word, 15, 325-40. doi:10.1080/00437956.1959.11659702 
Gorman, K. \& Johnson, D. (2013). Quantitative Analysis. In R. Bayley, R. Cameron, \& C. Lucas (Eds.), The Oxford Handbook of Sociolinguistics (pp. 214-240). Oxford: Oxford University Press.

Haeri, N. (1997). The Sociolinguistic Market of Cairo: Gender, Class, and Education. New York: Columbia University Press.

Horesh, U. (2000). Toward a Phonemic and Phonetic Assessment of Jaffa Arabic: Is It a Typical Urban Palestinian Dialect? Proceedings of the Third International Conference of AIDA (pp. 15-20). Association Internationale De Dialectologie Arabe (AIDA). Malta: Salesian.

Horesh, U. (2014). Phonological Outcomes of Language Contact in the Palestinian Arabic Dialect of Jaffa. Diss. University of Essex.

Johnson, D. (2009). Getting off the GoldVarb Standard: Introducing Rbrul for Mixed-Effects Variable Rule Analysis. Language and Linguistics Compass, 3(1), 359-83. doi:10.1111/j.1749-818X.2008.00108.x

Kerswill, P. (2002). Koineization and accommodation. In J.K. Chambers, P. Trudgill \& N. SchillingEstes (Eds.), The handbook of language variation and change (pp. 669-702). Oxford: Blackwell.

Labov, W. (1966). The Social Stratification of English in New York City. Washington D. C.: Center for Applied Linguistics.

Labov, W. (1990). The Intersection of Sex and Social Class in the Course of Linguistic Change. Language Variation and Change, 2, 205-54. doi:10.1017/So954394500000338

Labov, W. (1994). Principles of Linguistic Change. Vol. 1. Oxford: Blackwell.

Meyer, M. (1907). History of the City of Gaza. New York: Columbia University Press.

Milroy, L. (1987). Language and social networks. Oxford: Basil Blackwell.

Milroy, J. \& Milroy, L. (1985). Linguistic Change, Social Network and Speaker Innovation. Journal of Linguistics, 21(2), 339-84. doi:10.1017/So022226700010306

Monterescu, D. (2005). Spatial Relationality: Urban space and ethnic relations in Jewish-Arab mixed towns, 1948-2004. Diss. University of Chicago.

Morris, B. (2008). 1948: A History of the First Arab-Israeli War. New Haven Conn: Yale University Press.

Nagelkerke, N. J.D. (1991). A Note on a General Definition of the Coefficient of Determination. Biometrika, 78(3), 691-92. doi:10.1093/biomet/78.3.691

Palva, H. (2006). Dialects: Classification. In K. Versteegh (Eds.), Encyclopedia of Arabic Language and Linguistics (pp. 604-13). Boston: BRILL.

"Palestine Refugees." (2013). UNRWA. Retrieved from http://www.unrwa.org/palestine-refugees Pappe, I. (2006). The Ethnic Cleansing of Palestine. Oxford: Oneworld.

Salonen, E. (1979). Zum Arabischen Dialekt Von Gaza Teil I. Helsinki: Finnish Oriental Society. Salonen, E. (1980). Zum Arabischen Dialekt Von Gaza Teil II. Helsinki: Suomalainen Tiedeakatemia. Sankoff, D. (1975). VARBRUL version 2. Unpublished program and documentation.

Sankoff, D., Tagliamonte, S., \& Smith, E. (2005). GoldVarb X: a variable rule application for Macintosh and Windows. Retreived from http://individual.utoronto.ca/tagliamonte/goldvarb.html

Schmidt, R. (1974). Sociolinguistic Variation in Spoken Arabic in Egypt: A Reexamination of the Concept of Diglossia. Diss. Brown University.

Shahin, K. N. (2007). Palestinian Arabic. In K. Versteegh (Eds.), Encyclopedia of Arabic Language and Linguistics (pp. 526-38). Boston: BRILL.

Shorrab, G. (1981). Models of Socially Significant Linguistic Variation: The Case of Palestinian Arabic. Diss. State University of New York at Buffalo. 
Trudgill, P. (1972). Sex, Covert Prestige and Linguistic Change. Language in Society, 1(2), 179-95.

Trudgill, P. (1974). The Social Differentiation of English in Norwich. Cambridge: Cambridge University Press.

Trudgill, P. (1983). On Dialect: Social and Geographical Perspectives. Oxford: Basil Blackwell.

Woidich, M. (2009). Cairo Arabic. In K. Versteegh (Eds.), Encyclopedia of Arabic Language and Linguistics (pp. 323-33). Boston: BRILL. 